\title{
Neuromuscular Compartmentalization of the Vastus Medialis Muscle: Comparison of the Activity of the Vastus Medialis Obliquus and the Vastus Medialis Longus by High Density Electromyography
}

Compartimentación Neuromuscular del Músculo Vasto Medial: Comparación de la Actividad del
Vasto Medial Oblicuo y del Vasto Medial Largo Mediante Electromiografía de Alta Densidad

Rodrigo Guzmán-Venegas ${ }^{1}$; Oscar Valencia ${ }^{1}$; Eduardo L. Cadore $^{2}$ \& Mikel izquierdo Mat $^{3,4}$

GUZMÁN-VENEGAS, R.; VALENCIA, O.; CADORE, E. L. \& IZQUIERDO, M. Neuromuscular compartmentalization of the vastus medialis muscle: comparison of the activity of the vastus medialis obliquus and the vastus medialis longus by high density electromyography. Int. J. Morphol., 39(1):205-210, 2021.

SUMMARY: Anatomical studies describe the vastus medialis (VM) as being subdivided into two morphologically distinct components, the vastus medialis obliquus (VMO) and the vastus medialis longus (VML). However, there are discrepancies regarding the functional differentiation of these components. The aim of this study was to compare the levels of activation of the VMO and the VML by high density surface electromyography. Twelve healthy young women (age: $21.4 \pm 2.0$ years; weight: $58.1 \pm 7.5 \mathrm{~kg}$; height: $1.6 \pm 0.1$ $\mathrm{m})$, performed an open kinetic chain knee exercise during which the EMG activity of the VMO and the VML was recorded with twodimensional matrices of 32 surface electrodes. The exercises were performed with three levels of resistance (5, 10 and $15 \%$ of the body weight $(\mathrm{BW})$ ), considering three phases: concentric, isometric and excentric. In the isometric phase the VMO had greater activation than the VML with the three levels of resistance $(\mathrm{p}<0.05)$. In the excentric phase, the VMO also showed greater activation than the VML with the 10 and $15 \%$ BW resistance levels, while in the concentric phase, the VMO showed greater activity than the VML with only the $15 \%$ $\mathrm{BW}$ resistance. The results indicated significant differences in the activation level of the two components of the VM. This bears importance in the development of exercises intended to achieve a greater or more selective activation of the VMO. In the sample subjected to evaluation, the EMG recordings describe a greater activation of the VMO in comparison to the VML, which is more important in the isometric and excentric phases of the flexion/extension of the knee in an open kinetic chain. These findings suggest a functional compartmentalization of the VM.

KEY WORDS: Heterogeneous recruitment; Muscle activation pattern; Functional compartmentalization; Vastus medialis muscle.

\section{INTRODUCTION}

The vastus medialis muscle (VM) is one of the components of the quadriceps muscle, whose main function is the extension of the knee and which, in particular, has been attributed an active role in the medial stability of the patella (Waryasz \& McDermott, 2008). Hence the clinical importance of its function in relation to the aetiology and treatment of patellofemoral dysfunction. This is one of the most prevalent knee pathologies in the young population, especially in women (Smith et al. 2018). The stabilizing role of the VM is mainly due to the orientation of its muscle fibres, the direction of which determines a medialising component of the patella (Waryasz \& McDermott). Anatomical studies show there is a structural division of the VM into two elements, the vastus medialis obliquus (VMO) and the vastus medialis longus (VML) (Travnik et al. 1995; Smith et al. 2009; Rajput et al. 2017). The fibres of these components are oriented at $47^{\circ}$ and $15^{\circ}$ respectively from the longitudinal axis of the femur (Waryasz \& McDermott). This morphologic characteristic leads to the presumption that each of these two components fulfils different functions, given the orientation of their lines

\footnotetext{
${ }^{1}$ Laboratory LIBFE, Kinesiology School, Faculty of Medicine, Universidad de los Andes, Chile.

${ }^{2}$ School of Physical Education, Physiotherapy and Dance, Exercise Research Laboratory, Universidade Federal do Rio Grande do Sul, Porto Alegre, Brazil.

${ }^{3}$ Department of Health Sciences, Public University of Navarre, CIBER of Frailty and Healthy Aging (CIBERFES), Navarrabiomed, Pamplona, Navarre, Spain.

${ }^{4}$ Grupo GICAEDS. Programa de Cultura Física, Deporte y Recreación, Universidad Santo Tomás, Bogotá, Colombia.
} 
GUZMÁN-VENEGAS, R.; VALENCIA, O.; CADORE, E. L. \& IZQUIERDO, M. Neuromuscular compartmentalization of the vastus medialis muscle: comparison of the activity of the vastus medialis obliquus and the vastus medialis longus by high density electromyography. Int. J. Morphol., 39(1):205-210, 2021.

of force (Blazevich et al., 2006). In this context, the VML has been attributed primarily a knee extensor role, while the VMO is the only active medial stabilizer of the patella (Speakman $\&$ Weisberg, 1977). Several studies have attempted to demonstrate the functional differences between these two components, nevertheless, their conclusions differ (Hubbard \& Opersteny, 2002; Rainoldi et al., 2008; Spairani et al., 2012).

A possible explanation for this lies in the techniques used to obtain the EMG recordings. On the one hand, needle EMG involves taking an intramuscular recording with a reduced capture volume, reason for which its recordings involve a small number of motor units (MU) and thus its conclusions are limited to the activation of those few MU (Merletti \& Parker, 2004; Merletti et al., 2008). This may be solved with bipolar surface EMG, a technique which involves a larger capture volume, incrementing in this way the number of MU it is capable of recording. However, in the case of large muscles, such as the VMO and the VML, the ratio between the capture volume and the muscle volume continues to imply that it leads to conclusions based on recording a reduced number of the total amount of MU.

In contrast to the above, high density surface EMG (HD-sEMG) (Masuda et al., 1983; Saitou et al., 2000; Farina et al., 2002; Merletti et al., 2008) is a technique that employs a greater amount of electrodes arranged in one- or two-dimensional matrices which cover a large surface of the muscle being studied and thus a greater capture volume. Hence, the conclusions obtained with this technique imply a large number of MU and, consequently, also imply results which are possibly closer to reality (Merletti \& Parker).

The aim of this research was to compare the level of activation of the VMO to that of the VML in young women during a knee flexion/extension exercise using HD-sEMG to test the hypothesis that the VMO presents a greater level of activation than the VML, with the purpose of providing evidence of the functional or neuromuscular compartmentalization of the VM.

\section{MATERIAL AND METHOD}

A sample of 12 physically active young women (age: $21.4 \pm 2.0$ years; weight: $58.1 \pm 7.5 \mathrm{~kg}$; height: $1.6 \pm 0.1 \mathrm{~m}$ ) was evaluated in a cross sectional analytic observational study (Hernández \& Fernández, 2014). The following exclusion criteria were applied when recruiting volunteer participants: i) history of pain or pathology of the knee within the last 12 months, ii) medical history of central or peripheral neurological diseases, iii) injury or infection of the skin over the VM muscle, iv) substance abuse (alcohol and/or drugs) in the 48 hours prior to the evaluation, v) having performed strenuous physical activity in the 48 hours prior to the measurement. All volunteers provided written agreement signing an informed consent document. The procedures in this study were in accordance with the criteria of the Declaration of Helsinki and were approved by the local ethics committee (SCEC201603, 07-03-2016).

Exercise. The EMG activity of the VMO and the VML was recorded during an open kinetic chain flexion/extension exercise of the knee. The recordings were performed on the dominant knee of each volunteer determined on the basis of the lower limb selected most frequently to descend from a $30 \mathrm{~cm}$-high crate (Sadeghi et al., 2000). A quadriceps machine (503291, Enraf-Nonius B.V., Rotterdam, The Netherlands) was used to perform the exercise, limiting the range of movement between 90 and $0^{\circ}\left(0^{\circ}=\right.$ full extension of the knee). The exercise was performed with three levels of resistance, equivalent to 5, 10 and $15 \%$ of the body weight ( $\% \mathrm{BW}$ ) of each volunteer. The exercise was divided into three stages: i.- a concentric phase $\left(90^{\circ}\right.$ to $0^{\circ}$ extension); ii.an isometric phase (holding the $0^{\circ}$ position), and iii.- an excentric phase $\left(0^{\circ}\right.$ to $90^{\circ}$ flexion $)$.

The duration of each phase was 30, 10 and 30 seconds respectively, as shown in Figure 1. Additionally, an electrogoniometer (Delsys, Boston, Massachusetts, USA) was installed between the thigh and leg segments to control the speed of execution of the concentric and excentric phases $(3 \%$ $\mathrm{s})$. The recording of the electrogoniometer was superimposed over a predefined trapezoidal paradigm (Fig. 1C). Both were shown to the volunteers in a monitor placed in front of them so that they received feedback of the position and speed of the knee in real time. Based on this, volunteers were asked to follow the established paradigm through the electrogoniometer, which led to all of them performing the exercise at the same speed.

HD-sEMG recordings. The EMG activity of the VMO and the VML was recorded with two-dimensional matrices of 32 surface electrodes (ELSCH064NM3, modified, OTBiolettronica, Torino, Italy). They were placed over the VMO and the VML such that the rows of electrodes were parallel to the muscle fibres. For this, two lines were drawn at angles of $47^{\circ}$ and $15^{\circ}$ from the longitudinal axis of the femur (the line between the mid part of the superior end of the patella and the anterior superior iliac spine, Fig. 1A), for the VMO and the VML respectively (Waryasz \& McDermott). Before placing the electrodes, the skin was cleaned with an abrasive paste (Everi, Spes Medica s.r.l., Battipaglia, Italy) and washed with abundant water to diminish the impedance of the skin. 


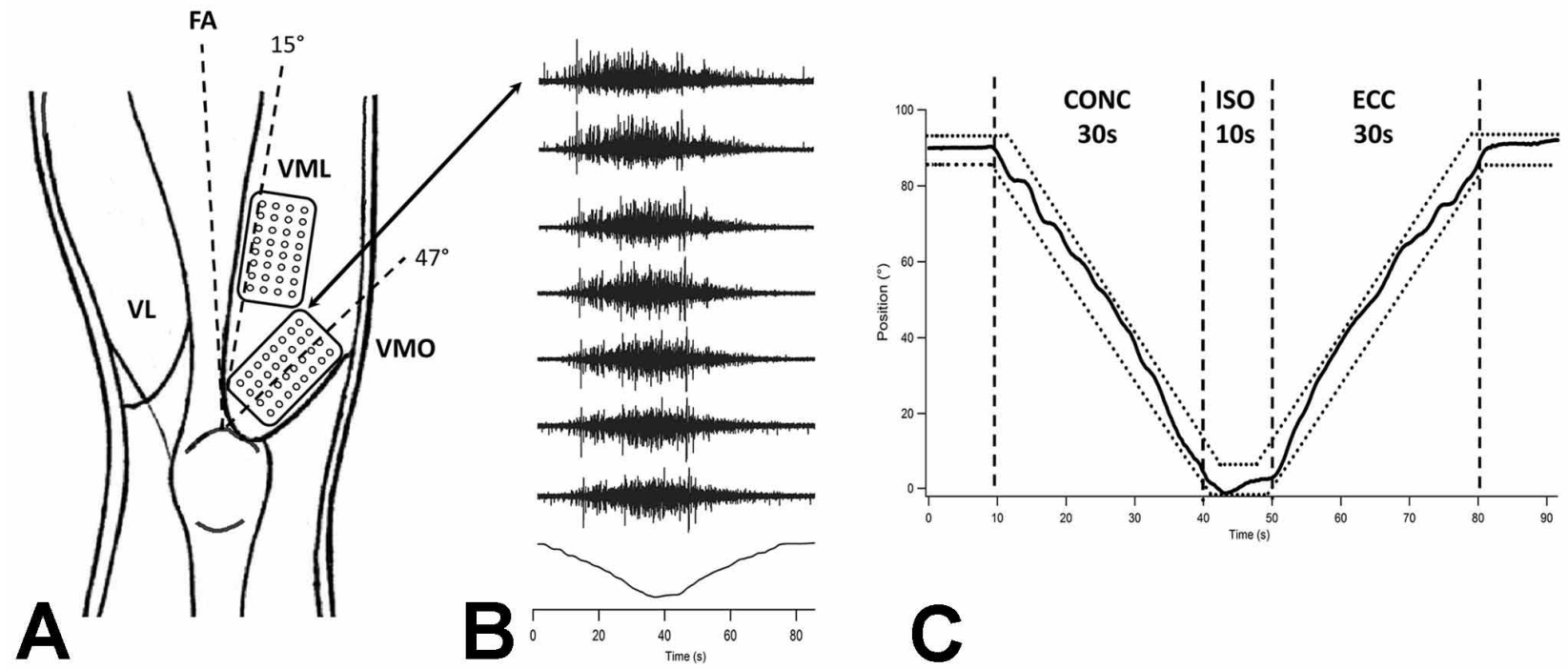

Fig. 1. A: Localisation of the electrode matrices for the vastus medialis obliquus (VMO) and the vastus medialis longus (VML). B: Example of eight EMG signals of one of the rows of the matrix of the VMO and the recording of the electrogoniometer. C: Paradigm of the knee position to be followed with the electrogoniometer signal by the volunteer participants. Also shown here are the three phases of the exercise. CONC: concentric; ISO: isometric and ECC: excentric.

The EMG signals of each matrix were amplified in a simple differential mode with a gain of 2000 units in a bandwidth of 10-500 Hz. The EMG signals and the electrogoniometer were digitalised in a synchronised manner at a sampling frequency of $2048 \mathrm{~Hz}$, with 12-bit resolution (EMG-USB2, OTBioelettronica, Torino, Italy).

Each volunteer performed at least three test repetitions for each resistance level in order to become familiar with the procedure. Then, the order in which the resistance $(5,10$ and $15 \% \mathrm{BW}$ ) was to be applied in the exercises was assigned by a simple randomisation. A five minute rest was considered between repetitions. Three repetitions of the exercise were performed for each resistance level.

HD-sEMG data processing. In the analysis of the EMG signals the second repetition of each resistance level was considered. From both electrode matrices, 28 EMG signals were obtained for each component of the VM (VMO and VML). These signals were filtered digitally with a fourth order Butterworth type pass filter of $20-400 \mathrm{~Hz}$. The analysis of the signals was performed considering the three phases of the exercise (concentric, isometric, and excentric), which were identified on the basis of the recording of the electrogoniometer (Fig. 1C). To represent the activation of the MU of the VMO and the VML, the amplitude of the 28 signals of each matrix was calculated with the root mean square (RMS) using a window of $250 \mathrm{~ms}$ without overlap (Guzmán-Venegas et al., 2015). To represent the level of activation of the VMO and the VML, the amplitudes of the 28 signals of each matrix were calculated. For example, for the $5 \% \mathrm{BW}$ resistance, the activation of the $\mathrm{VMO}$ in each

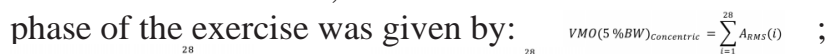

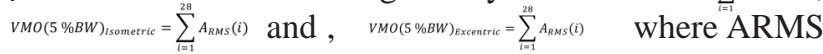
represents the EMG amplitude of each signal recorded in the matrix corresponding to each component of the VM. All the analyses were done with a data processing software (IgorPro 6.2., WaveMetrics, Portland, OR, USA).

Statistical analyses. The data were initially subjected to a descriptive statistical analysis in which the Shapiro-Wilk test was applied to determine whether the data distribution fulfilled the assumption of normality. The comparisons between the VMO and the VML were done with a t-test. All the analyses were carried out with a statistical significance level of $95 \%$ and one tail. The statistically significant differences were associated to a p-value of $<0.05$ (GraphPad $8 v$ Software, San Diego, California, USA).

\section{RESULTS}

The data revealed that the VMO generates a greater activation than the VML during the isometric phase with the three levels of resistance $(\mathrm{p}<0.05)$. Likewise, in the excentric phase, a greater activation was recorded for the VMO than for the VML in the 10 and $15 \%$ BW resistance levels, while in the concentric phase the VMO showed greater activity than the VML only in the $15 \%$ BW resistance level. Table I and Figure 2 show the activation levels of the VMO and the VML in the different phases and resistance levels. 

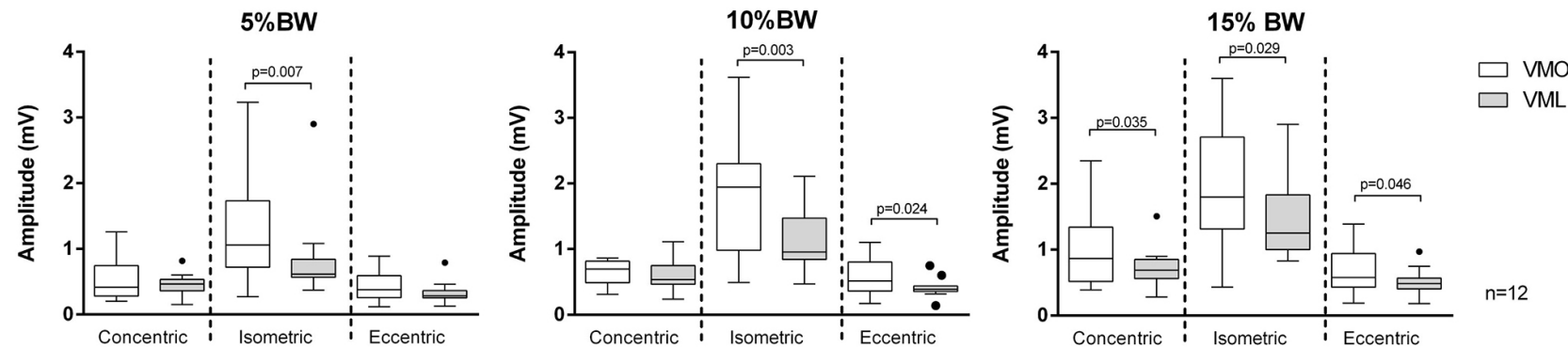

Fig. 2. EMG amplitudes (mV) of the vastus medialis obliquus (VMO) and the vastus medialis longus (VML) during an open kinetic chain knee extension exercise, with three different levels of resistance $(5,10$ and $15 \%$ body weight [ \% BW]). Each level is analysed in its three phases: concentric $\left(90-0^{\circ}\right)$, isometric $\left(0^{\circ}\right)$, and excentric $\left(0-90^{\circ}\right) .0^{\circ}$ : full extension of the knee $(\mathrm{n}=12)$.

Table I. Amplitude sEMG of VMO and VML in young healthy women $(n=12)$ during open chain flexion/extension knee exercise with different levels or resistance $(5,10$ and $15 \% \mathrm{BW})$.

\begin{tabular}{|c|c|c|c|c|c|c|}
\hline \multirow[b]{2}{*}{$\mathrm{n}=12$} & \multicolumn{2}{|c|}{$5 \% \mathrm{BW}$} & \multicolumn{2}{|c|}{$10 \% \mathrm{BW}$} & \multicolumn{2}{|c|}{$15 \% \mathrm{BW}$} \\
\hline & VMO & VML & VMO & VML & VMO & VML \\
\hline Concentric $(\mathrm{mV})$ & $0.53(0.33)$ & $0.46(0.16)$ & $0.66(0.19)$ & $0.61(0.26)$ & $1.00(0.58)^{d}$ & $0.72(0.30)^{d}$ \\
\hline Is ometric (mV) & $1.25(0.78)^{a}$ & $0.85(0.67)^{\mathrm{a}}$ & $1.77(0.90)^{b}$ & $1.11(0.45)^{b}$ & $2.03(0.95)^{\mathrm{e}}$ & $1.48(0.64)^{\mathrm{e}}$ \\
\hline Excen tric $(\mathrm{mV})$ & $0.43(0.24)$ & $0.33(0.17)$ & $0.58(0.28)^{\mathrm{c}}$ & $0.42(0.15)^{c}$ & $0.70(0.37)^{f}$ & $0.51(0.20)^{f}$ \\
\hline
\end{tabular}

\%BW: percent of body weight; VMO: vastus medial oblique; VML: vastus medial longitudinal; $\mathrm{mV}$ : millivolts. ap=0.007; $\mathrm{b}=0.003 ; \mathrm{c}=0.024 ; \mathrm{d}=0.035$; $\mathrm{e}=0.029 ; \mathrm{f}=0.046$

\section{DISCUSSION}

The results of this study show that the VMO has a greater activation level than the VML in the open kinetic chain flexion/extension exercise of the knee subjected to evaluation. This may show a functional difference between both components of the VM. These differences wereidentified in the isometric phase with all resistance levels. Similar findings have been reported by Hubbard \& Opersteny who, among several exercises, studied the EMG of the VMO and the VML during the maintained knee extension, similar to the isometric phase analysed in the present study. In contrast, Spairani et al. reported a greater activation of the VMO than the VML in open and closed kinetic chain knee extension exercises. Differing from our study, these authors analysed static exercises focusing on the resistance of local muscle fatigue, based on the difference in the distribution of the type of muscle fibres between the VMO and the VML described by Rainoldi et al. (2008). The discrepancy with our results may also be attributed to the characteristics of the matrices used in the study of Spairani et al., who used 4 electrodes (HD-sEMG) arranged in a single dimension, analysing only three signals to characterise the VMO vs. the VML, whereas in our study 28 signals were analysed for each component of the VM, implying that a larger number of MU were recorded during the exercises. Secondly, the levels of contraction appear to be important to determine the functional differentiation between the regions of a same muscle. In our study, the VMO showed greater activation than the VML with all levels of resistance for the isometric phase, while in the excentric phase the differences became evident from $10 \% \mathrm{BW}$ and for the concentric phase they were only observed with the $15 \%$ $\mathrm{BW}$ resistance level. This shows that the differences in activation between the VMO and the VML are independent of the external resistance in the case of the isometric contraction whereas in the dynamic contractions said difference is dependent on the level of external resistance. This may indicate that the greater engagement of the VMO over the VML in dynamic conditions could be associated with a certain level of resistance and such differential activation would not be evident with either higher or lower resistance levels. In this context, prior studies in the superficial masseter muscle (Guzmán-Venegas et al.) have demonstrated the existence of a functional compartmentalization only at submaximal levels of isometric contractions (20-60\% MVC), while at higher percentages of the MVC this difference disappears.

The resistance levels used in the present study were relatively low, which could have had an effect on the differences in activation between the VMO and the VML. 
GUZMÁN-VENEGAS, R.; VALENCIA, O.; CADORE, E. L. \& IZQUIERDO, M. Neuromuscular compartmentalization of the vastus medialis muscle: comparison of the activity of the vastus medialis obliquus and the vastus medialis longus by high density electromyography. Int. J. Morphol., 39(1):205-210, 2021.

The levels of external resistance used in this study were chosen on the basis of the recommendations provided in protocols of rehabilitation of the femoropatellar dysfunction in the acute and subacute phases (Witvrouw et al., 2000, 2004), where activation of the VMO is key.

One of the main novelties of the present study is the application of recording the VMO and VML muscle activity in the dynamic phases of the flexion/extension exercise of the knee. Our results show there is greater activation of the VMO than of the VML in the excentric phase (10-15\% BW) and the concentric phase ( $15 \% \mathrm{BW}$ only). These findings differ from those reported by Hubbard \& Opersteny, who did not find significant differences in the level of activation between the VMO and the VML. Nevertheless, a recent study by Gallina et al. (2017) supports our findings: they showed that, in young people, the nervous system is capable of activating different regions of the VM in a heterogeneous manner, providing a neuromuscular basis for the functional division of this muscle.

The functional or neuromuscular compartmentalization demonstrated in this work is consistent with that described in other skeletal muscles. Staudenmann et al. (2009) recorded the differential activation of the different regions of the triceps surae in relation to movements of the foot and the direction of the force of reaction of the floor. Moreside $e t a l$. (2008) demonstrated the existence of differential recruitment of the upper and lower portions of the rectus abdominis muscle in different exercises of low intensity. While studying the recruitment of different regions of the rectus femoris in exercises combining hip flexion and knee extension, Watanabe et al. (2012) demonstrated the presence of at least two regions with differential recruitment.

One of the limitations of the present study is the precision in the alignment of the rows of electrodes in relation to the muscle fibers. This shortcoming could be addressed in future studies by ultrasonography during the procedure of positioning the matrix. However, given that in the present study only the amplitude of the EMG was analysed, said orientation is not crucial, unlike its influence in the determination of other EMG parameters such as the muscle fibre conduction velocity (Rainoldi et al., 2000; Merletti et al., 2003; Farina et al., 2004).

The results obtained in this study provide the basis to consider the feasibility of activation exercises that recruit the VMO in a more selective manner, as demonstrated in the isometric and exentric phases of the exercise analysed in this study. Future research should be designed to evaluate the effectiveness of the type of exercise analysed in this investigation in the rehabilitation and prevention of patellofemoral dysfunctions.

\section{CONCLUSION}

In the sample analysed, the EMG recordings describe a greater activation of the VMO when compared to the $\mathrm{VML}$, this being more important in the isometric and excentric phases of the open kinetic chain flexion/extension of the knee. These findings suggest a functional compartmentalization of the VM.

\section{ACKNOWLEDGEMENTS}

The authors thank S. Haro, K. Ibarra, M. Jara, M.P. Orlandini and A. Quintana for their technical assistance during the collection of data.

GUZMÁN-VENEGAS, R.; VALENCIA, O.; CADORE, E. L. \& IZQUIERDO, M. Compartimentación neuromuscular del músculo vasto medial: comparación de la actividad del vasto medial oblicuo y del vasto medial largo mediante electromiografía de alta densidad. Int. J. Morphol., 39(1):205-210, 2021.

RESUMEN: Los estudios anatómicos describen que el músculo vasto medial (VM) se subdivide en dos componentes morfológicamente distintos, el vasto medial obliquus (VMO) y el vasto medial largo (VML). Sin embargo, existen discrepancias con respecto a la diferenciación funcional de estos componentes. El objetivo de este estudio fue comparar los niveles de activación del VMO y el VML mediante electromiografía de superficie de alta densidad. Doce mujeres jóvenes sanas (edad: $21,4 \pm 2,0$ años; peso: $58,1 \pm 7,5 \mathrm{~kg}$; altura: $1,6 \pm 0,1 \mathrm{~m}$ ), realizaron un ejercicio de rodilla de cadena cinética abierta durante el cual se registró la actividad EMG de la VMO y la VML con dos matrices dimensionales de 32 electrodos de superficie. Los ejercicios se realizaron con tres niveles de resistencia (5, 10 y $15 \%$ del peso corporal (PC)), considerando tres fases: concéntrica, isométrica y excéntrica. En la fase isométrica el VMO tuvo mayor activación que el VML con los tres niveles de resistencia $(\mathrm{p}<0,05)$. En la fase excéntrica, el VMO también mostró mayor activación que el VML con los niveles de resistencia de 10 y $15 \% \mathrm{BW}$, mientras que en la fase concéntrica, el VMO mostró mayor actividad que el VML con solo el $15 \%$ de resistencia al BW. Los resultados indicaron diferencias significativas en el nivel de activación de los dos componentes de la VM. Esto tiene importancia en el desarrollo de ejercicios destinados a lograr una activación mayor o más selectiva del VMO. En la muestra sometida a evaluación, los registros EMG describen una mayor activación del VMO en comparación con el VML, que es más importante en las fases isométrica y excéntrica de la flexión / extensión de la rodilla en cadena cinética abierta. Estos hallazgos sugieren una compartimentación funcional de la VM.

PALABRAS CLAVES: Reclutamiento heterogéneo; Patrón de activación muscular; Compartimentación funcional; Músculo vasto medial. 


\section{REFERENCES}

Blazevich, A. J.; Gill, N. D. \& Zhou, S. Intra- and intermuscular variation in human quadriceps femoris architecture assessed in vivo. J. Anat., 209(3):289-310, 2006

Farina, D.; Fosci, M. \& Merletti, R. Motor unit recruitment strategies investigated by surface EMG variables. J. Appl. Physiol. (1985), 92(1):235-47, 2002.

Farina, D.; Pozzo, M.; Merlo, E.; Bottin, A. \& Merletti, R. Assessment of average muscle fiber conduction velocity from surface EMG signals during fatiguing dynamic contractions. IEEE Trans. Biomed. Eng., 51(8):1383-93, 2004.

Gallina, A.; Blouin, J. S.; Ivanova, T. D. \& Garland, S. J. Regionalization of the stretch reflex in the human vastus medialis. J. Physiol., 595(14):4991-5001, 2017.

Guzmán-Venegas, R. A.; Biotti Picand, J. L. \& Berral de la Rosa, F. J. Functional compartmentalization of the human superficial masseter muscle. PLoS One, 10(2):e0116923, 2015.

Hernández, R. \& Fernández, C. B. Metodología de la Investigación. Ciudad de México, McGraw-Hill Education, 2014.

Hubbard, J. K. \& Opersteny, S. EMG analysis of two portions of the vastus medialis muscle during selected knee rehabilitation exercises. J. Musculoskelet. Res., 6(2):107-18, 2002.

Masuda, T.; Miyano, H. \& Sadoyama, T. The propagation of motor unit action potential and the location of neuromuscular junction investigated by surface electrode arrays. Electroencephalogr. Clin. Neurophysiol., 55(5):594-600, 1983.

Merletti, R. \& Parker, P. Electromyography. Physiology, Engineering and Noninvasive Aplications. Hoboken, New Jersey, John Wiley \& Sons, 2004.

Merletti, R.; Farina, D. \& Gazzoni, M. The linear electrode array: a useful tool with many applications. J. Electromyogr. Kinesiol., 13(1):37-47, 2003.

Merletti, R.; Holobar, A. \& Farina, D. Analysis of motor units with highdensity surface electromyography. J. Electromyogr. Kinesiol., 18(6):879-90, 2008.

Moreside, J. M.; Vera-Garcia, F. J. \& McGill, S. M. Neuromuscular independence of abdominal wall muscles as demonstrated by middleeastern style dancers. J. Electromyogr. Kinesiol., 18(4):527-37, 2008.

Rainoldi, A.; Falla, D.; Mellor, R.; Bennell, K. \& Hodges, P. Myoelectric manifestations of fatigue in vastus lateralis, medialis obliquus and medialis longus muscles. J. Electromyogr. Kinesiol., 18(6):1032-7, 2008.

Rainoldi, A.; Nazzaro, M.; Merletti, R.; Farina, D.; Caruso, I. \& Gaudenti, S. Geometrical factors in surface EMG of the vastus medialis and lateralis muscles. J. Electromyogr. Kinesiol., 10(5):327-36, 2000.

Rajput, H. B.; Rajani, S. J. \& Vaniya, V. H. Variation in morphometry of vastus medialis muscle. J. Clin. Diagn. Res., 11(9):AC01-AC04, 2017.

Sadeghi, H.; Allard, P.; Prince, F. \& Labelle, H. Symmetry and limb dominance in able-bodied gait: a review. Gait Posture, 12(1):34-45, 2000.

Saitou, K.; Masuda, T.; Michikami, D.; Kojima, R. \& Okada, M. Innervation zones of the upper and lower limb muscles estimated by using multichannel surface EMG. J. Hum. Ergol. (Tokyo), 29(12):35-52, 2000

Smith, B. E.; Selfe, J.; Thacker, D.; Hendrick, P.; Bateman, M.; Moffatt, F.; Rathleff, M. S.; Smith, T. O. \& Logan, P. Incidence and prevalence of patellofemoral pain: A systematic review and meta-analysis. PLoS One, 13(1): $0190892,2018$.

Smith, T. O.; Nichols, R.; Harle, D. \& Donell, S. T. Do the vastus medialis obliquus and vastus medialis longus really exist? A systematic review. Clin. Anat., 22(2):183-99, 2009.
Spairani, L.; Barbero, M.; Cescon, C.; Combi, F.; Gemelli, T.; Giovanetti, G.; Magnani, B. \& D'Antona, G. An electromyographic study of the vastii muscles during open and closed kinetic chain submaximal isometric exercises. Int. J. Sports Phys. Ther, 7(6):617-26, 2012.

Speakman, H. G. \& Weisberg, J. The vastus medialis controversy. Physiotherapy, 63(8):249-54, 1977.

Staudenmann, D.; Kingma, I.; Daffertshofer, A.; Stegeman, D. F. \& van Dieën, J. H. Heterogeneity of muscle activation in relation to force direction: a multi-channel surface electromyography study on the triceps surae muscle. J. Electromyogr. Kinesiol., 19(5):882-95, 2009.

Travnik, L.; Pernus, F. \& Erzen, I. Histochemical and morphometric characteristics of the normal human vastus medialis longus and vastus medialis obliquus muscles. J. Anat., 187(Pt. 2):403-11, 1995.

Waryasz, G. R. \& McDermott, A. Y. Patellofemoral pain syndrome (PFPS): a systematic review of anatomy and potential risk factors. Dyn. Med., 7:9, 2008.

Watanabe, K.; Kouzaki, M. \& Moritani, T. Task-dependent spatial distribution of neural activation pattern in human rectus femoris muscle. J. Electromyogr. Kinesiol., 22(2):251-8, 2012.

Witvrouw, E.; Danneels, L.; Van Tiggelen, D.; Willems, T. M. \& Cambier, D. Open versus closed kinetic chain exercises in patellofemoral pain a 5-year prospective randomized study. Am. J. Sports Med., 32(5):1122-30, 2004.

Witvrouw, E.; Lysens, R.; Bellemans, J.; Peers, K. \& Vanderstraeten, G. Open versus closed kinetic chain exercises for patellofemoral pain A prospective, randomized study. Am. J. Sports Med., 28(5):68794, 2000.

Corresponding autor:

Rodrigo Guzmán-Venegas.

Av. Monseñor Álvaro del Portillo 12.455

Las Condes

Santiago - RM

CHILE

Email: rguzman@uandes.cl.

Received: 08-09-2020

Accepted: 27-10-2020 